\title{
Photophysical Properties and Photobiological Activities of Ruthenium(II) Complexes Bearing m-Expansive Cyclometalating Ligands with Thienyl Groups
}

Julia McCain, ${ }^{\dagger}$ Katsuya L. Colón, ${ }^{\ddagger}$ Patrick C. Barrett, ${ }^{\ddagger}$ Susan M. A. Monro, ${ }^{\dagger}$ Tariq Sainuddin, ${ }^{\dagger}$ John Roque III, ${ }^{\ddagger}$ Mitch Pinto, ${ }^{\dagger}$ Huimin Yin, ${ }^{\dagger}$ Colin G. Cameron, ${ }^{\ddagger}$ Sherri A. McFarland*,†,‡

${ }^{\dagger}$ Department of Chemistry, Acadia University, Wolfville, Nova Scotia B4P 2 R6 Canada

‡Department of Chemistry and Biochemistry, The University of North Carolina at Greensboro, Greensboro, North Carolina 27402, United States

Supporting Information

Page

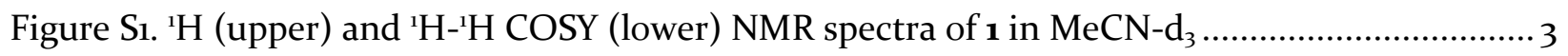

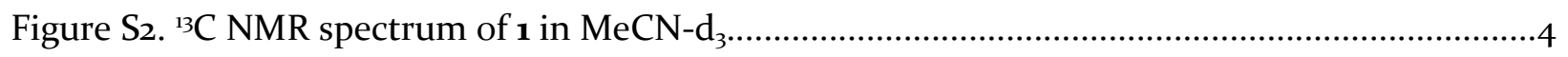

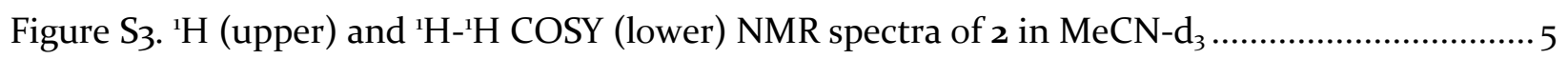

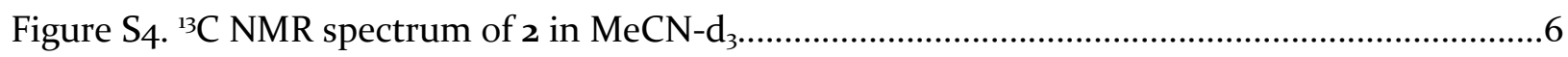

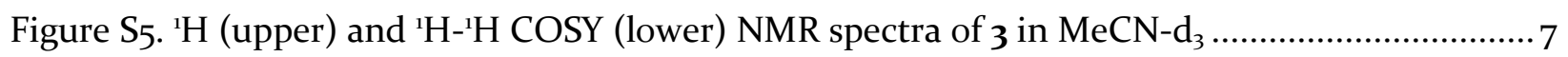

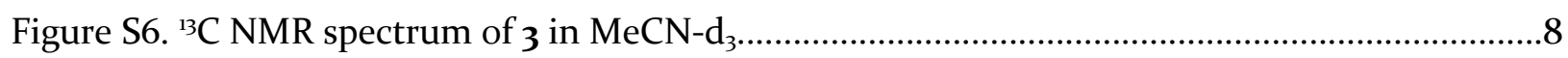

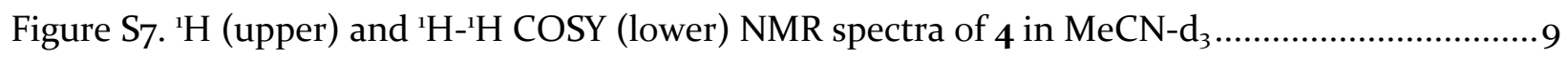

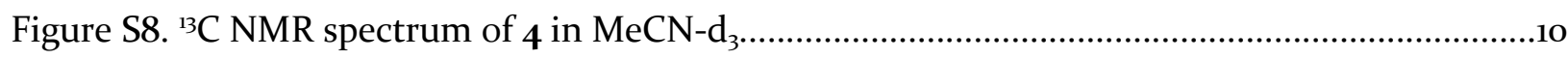

Figure S9. HPLC chromatogram of $\mathbf{1}$ collected at the following wavelengths: 270, 350, 450, 555

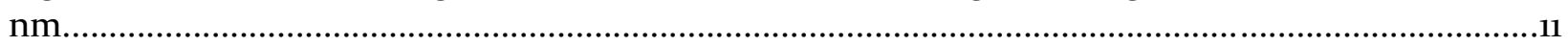

Figure Sio. HPLC chromatogram of 2 collected at the following wavelengths: 400, 285, 440, 490

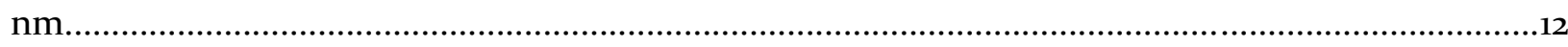

Figure S11. HPLC chromatogram of 3 collected at the following wavelengths: $400,285,440,490$

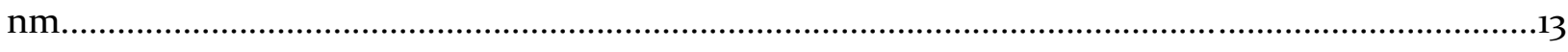

Figure S12. HPLC chromatogram of 4 collected at the following wavelengths: 270, 350, 450, 555

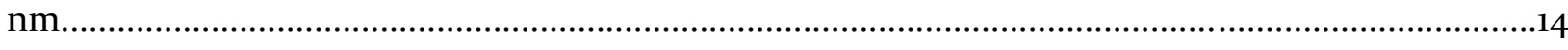

Figure S13. Comparison of the transient absorption decays for $\mathrm{Ru}(\mathrm{II}) \mathrm{C}^{\wedge} \mathrm{N}$ complex 1 collected with $\lambda_{\text {pump }}=355 \mathrm{~nm}(\mathrm{~A})$ or $532 \mathrm{~nm}(\mathrm{~B})$...

Figure S14. Comparison of the transient absorption decays for $\mathrm{Ru}(\mathrm{II}) \mathrm{C}^{\wedge} \mathrm{N}$ complex 2 collected with $\lambda_{\text {pump }}=355 \mathrm{~nm}(\mathrm{~A})$ or $532 \mathrm{~nm}(\mathrm{~B})$.

Figure S15. Comparison of the transient absorption decays for $\mathrm{Ru}(\mathrm{II}) \mathrm{C}^{\wedge} \mathrm{N}$ complex 3 collected

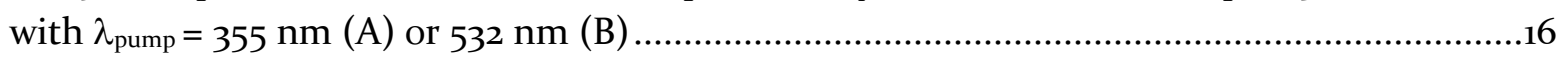


Figure S16. Comparison of the transient absorption decays for $\mathrm{Ru}(\mathrm{II}) \mathrm{C}^{\wedge} \mathrm{N}$ complex 4 collected

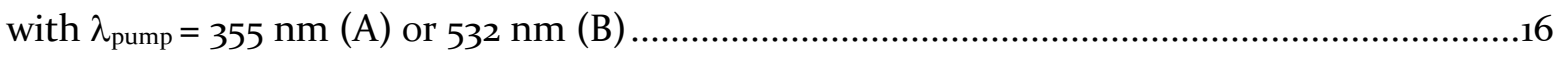

Figure $\mathrm{S}_{17}$. The TA spectrum of 4 excited at $532 \mathrm{~nm}$..............................................................

Figure S18. Transient absorption of the IBQ4T ligand only, in DMSO containing 1M KI. The

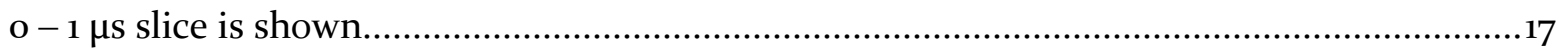

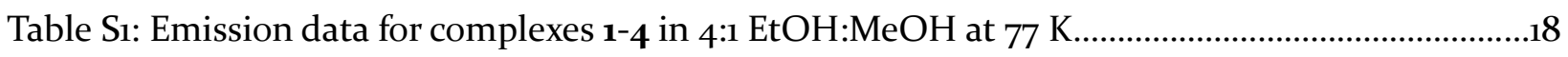



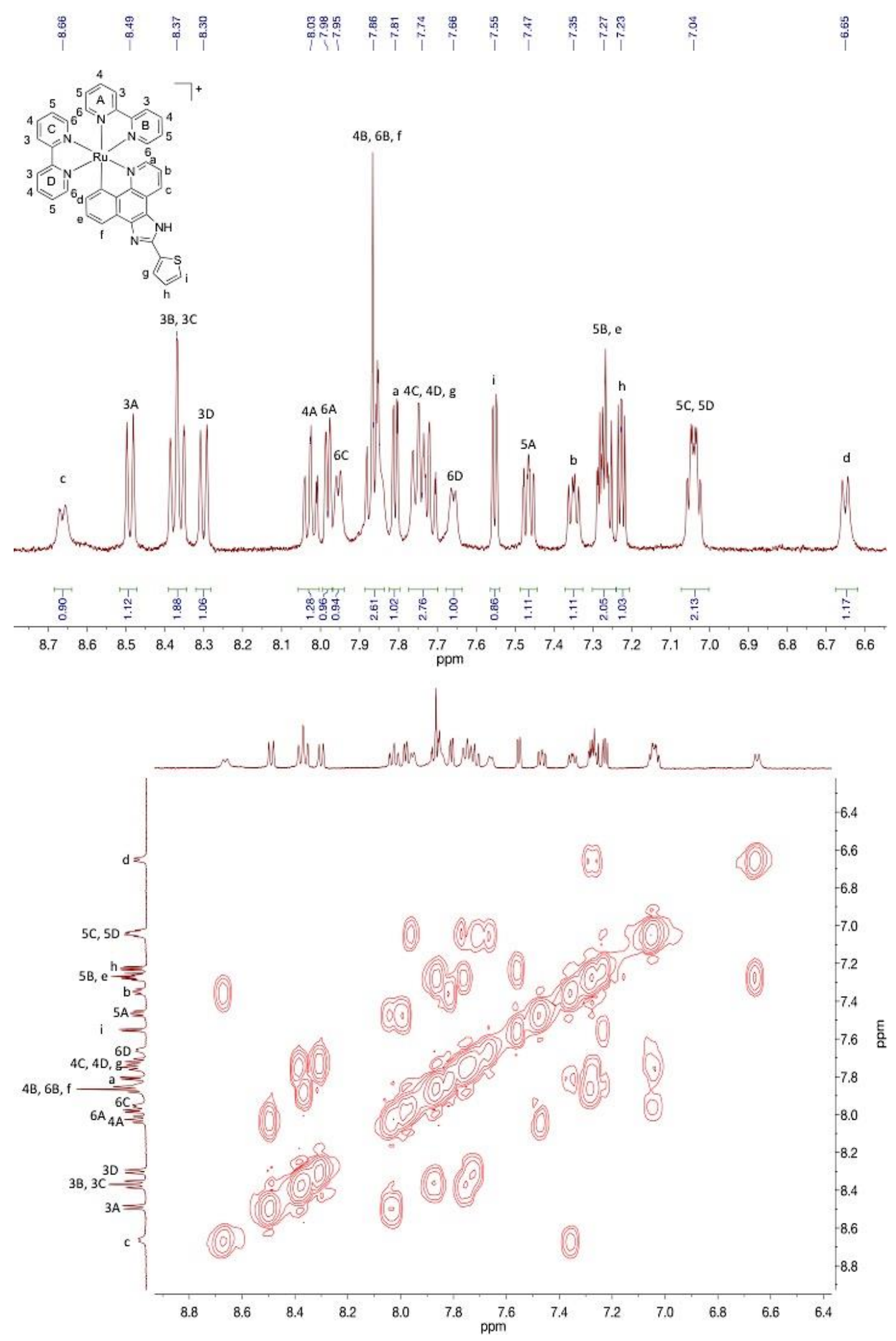

Figure S1. ${ }^{1} \mathrm{H}$ (upper) and ${ }^{1} \mathrm{H}-{ }^{1} \mathrm{H}$ COSY (lower) NMR spectra of $\mathbf{1}$ in $\mathrm{MeCN}-\mathrm{d}_{3}$. 


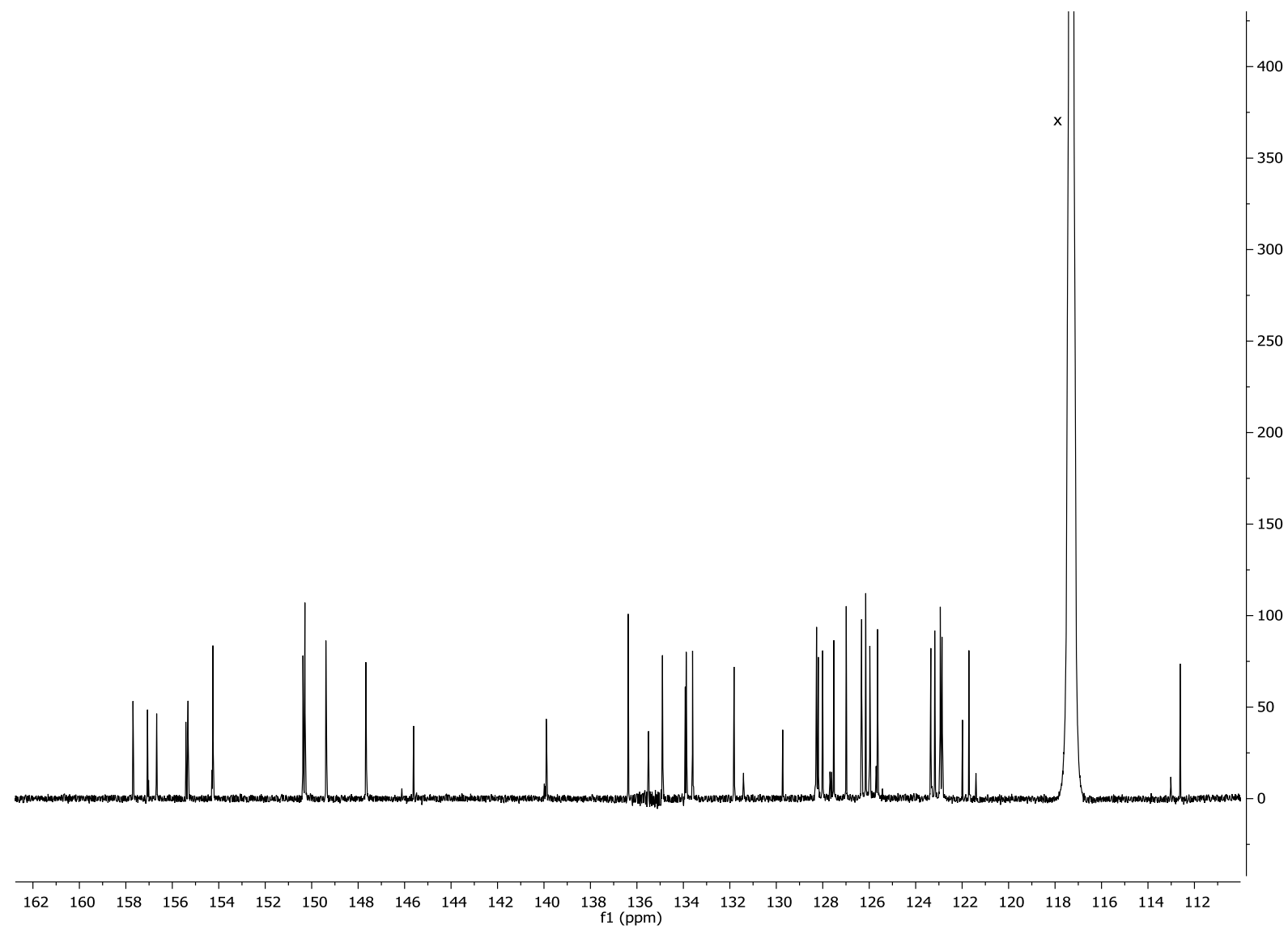

Figure S2. ${ }^{13} \mathrm{C}$ NMR spectrum of 1 in $\mathrm{MeCN}_{-} \mathrm{d}_{3}, 176 \mathrm{MHz} . \mathrm{X}=\mathrm{MeCN}$. 


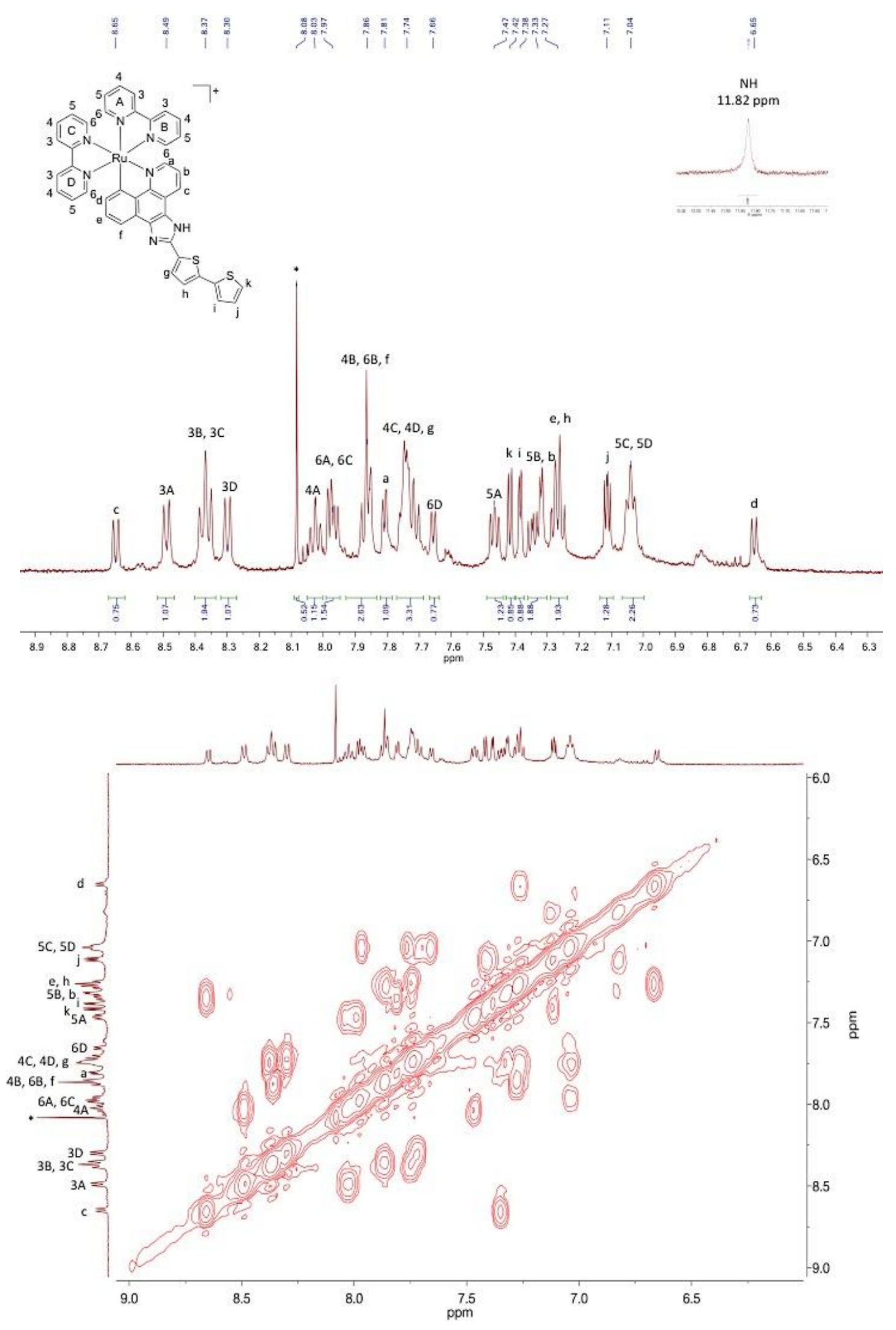

Figure $\mathrm{S}_{3} .{ }^{1} \mathrm{H}$ (upper) and ${ }^{1} \mathrm{H}-{ }^{1} \mathrm{H}$ COSY (lower) NMR spectra of 2 in $\mathrm{MeCN}-\mathrm{d}_{3}$. 


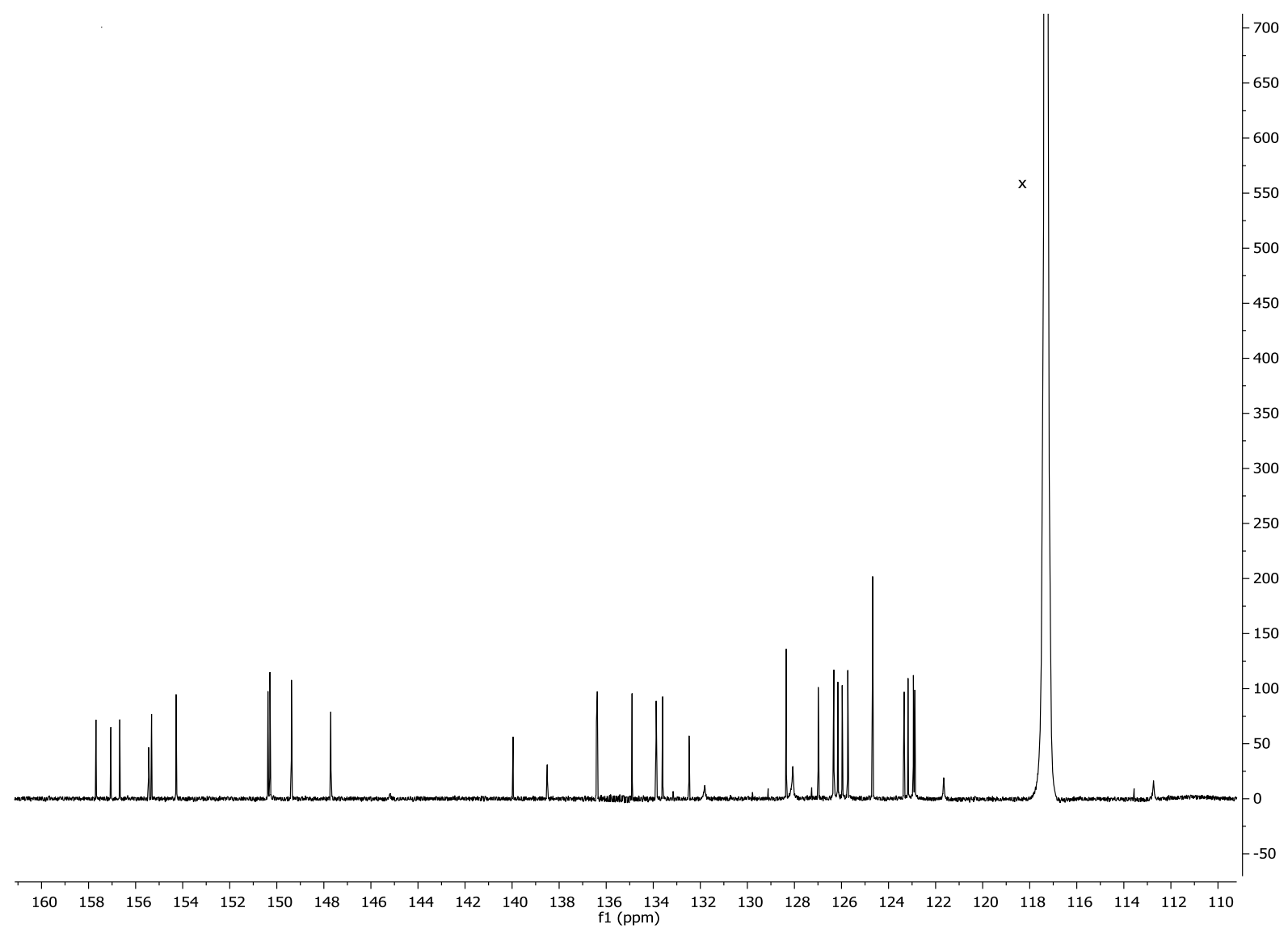

Figure $\mathrm{S}_{4} \cdot{ }^{13} \mathrm{C}$ NMR spectrum of 2 in $\mathrm{MeCN}_{-} \mathrm{d}_{3}, 176 \mathrm{MHz} . \mathrm{X}=\mathrm{MeCN}$. 

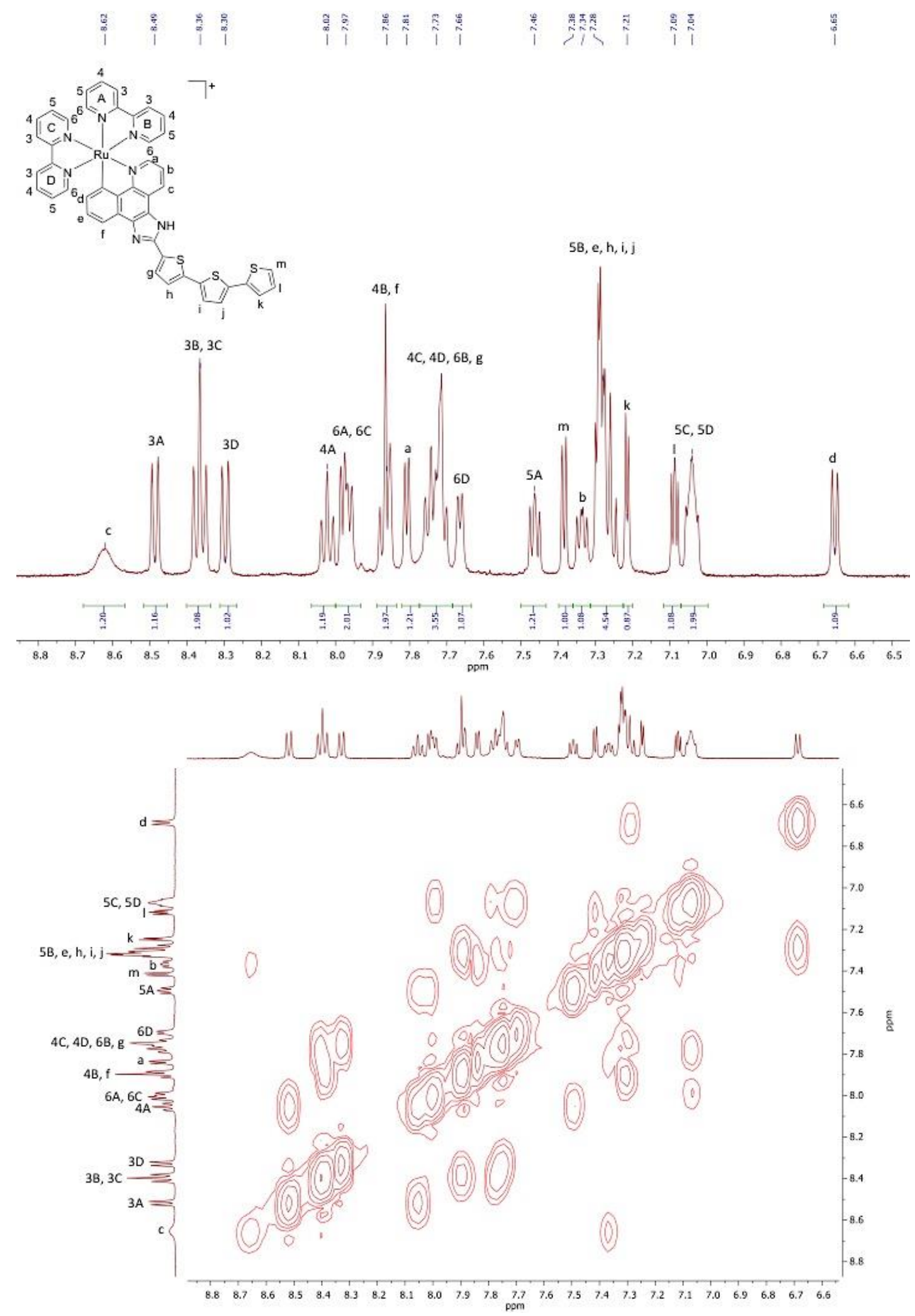

Figure $\mathrm{S}_{5} .{ }^{1} \mathrm{H}$ (upper) and ${ }^{1} \mathrm{H}-{ }^{1} \mathrm{H}$ COSY (lower) NMR spectra of 3 in $\mathrm{MeCN}-\mathrm{d}_{3}$. 


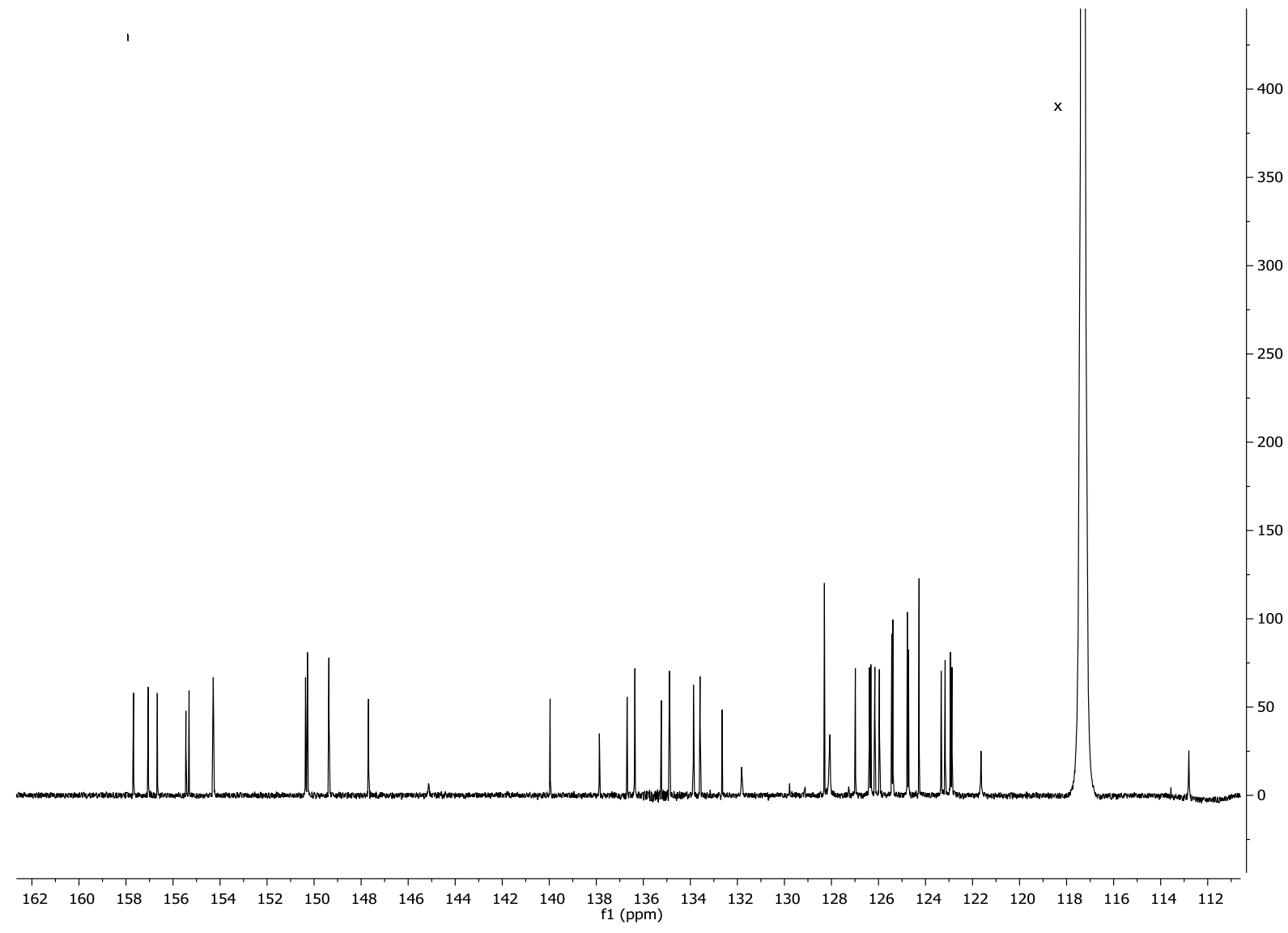

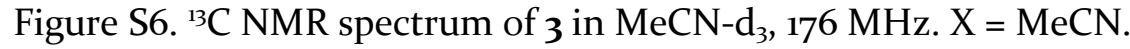



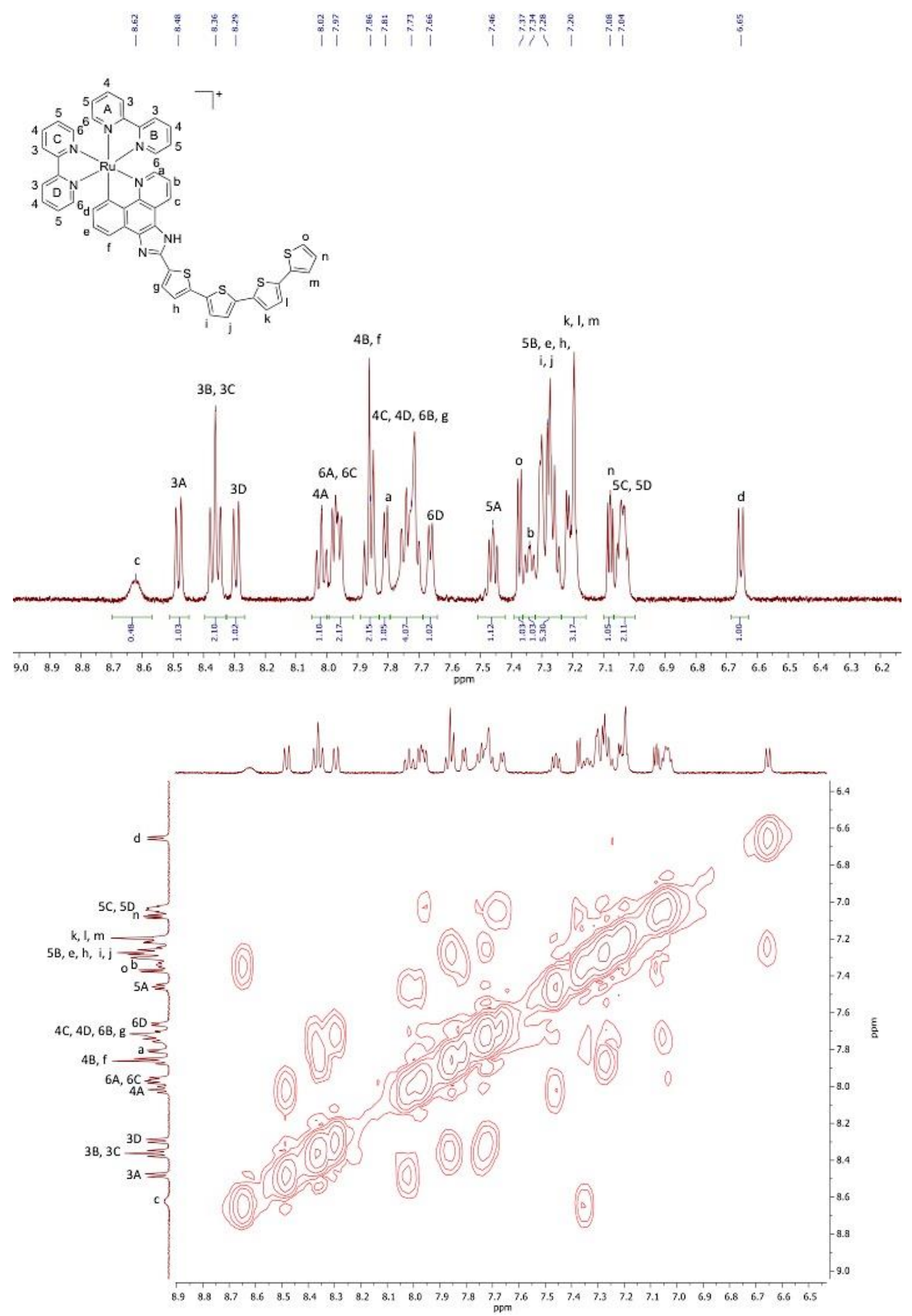

Figure $\mathrm{S}_{7}{ }^{1} \mathrm{H}$ (upper) and ${ }^{1} \mathrm{H}-{ }^{1} \mathrm{H}$ COSY (lower) NMR spectra of 4 in $\mathrm{MeCN}-\mathrm{d}_{3}$. 


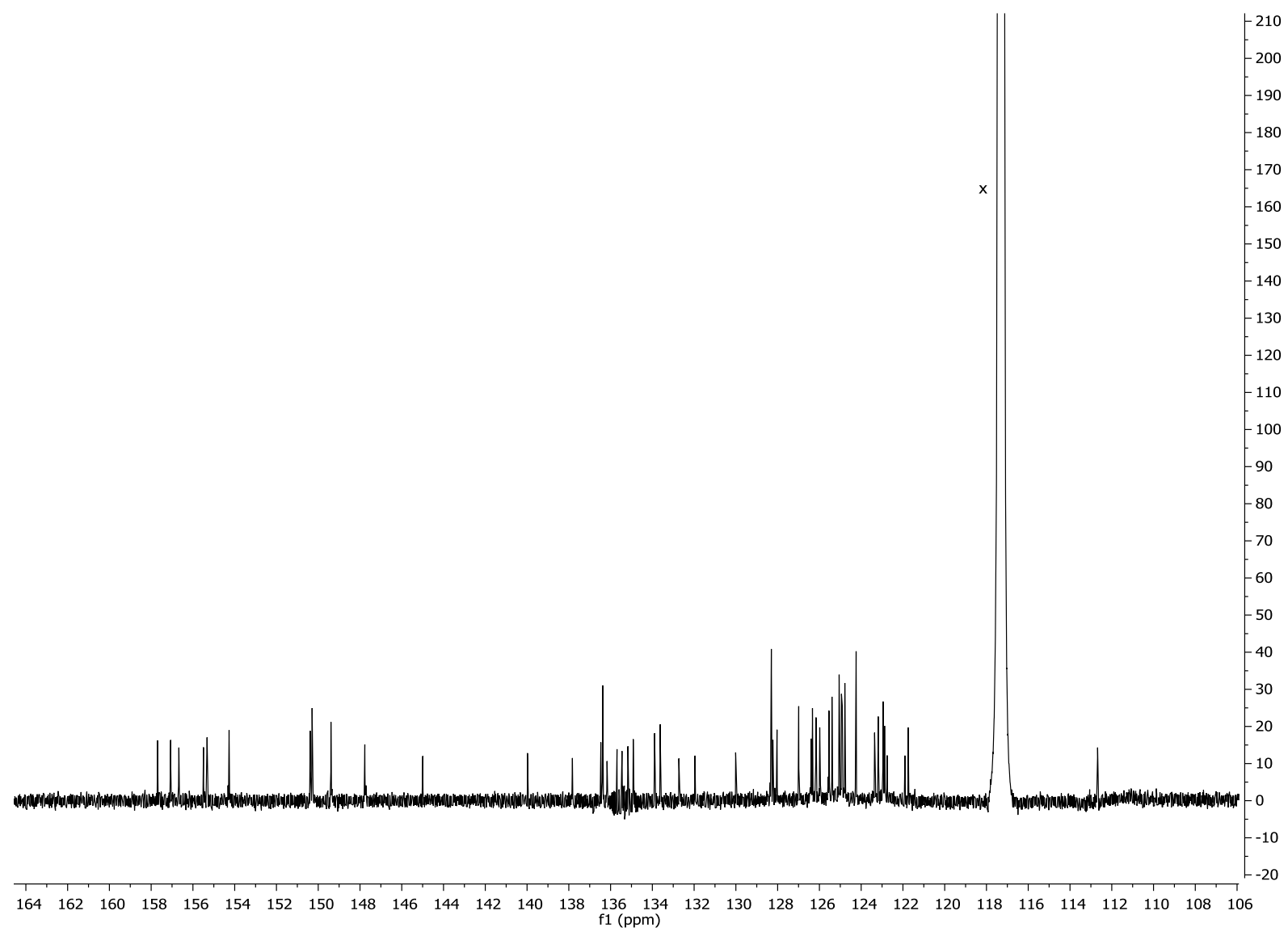

Figure S8. ${ }^{13} \mathrm{C}$ NMR spectrum of 4 in $\mathrm{MeCN}-\mathrm{d}_{3} .176 \mathrm{MHz} . \mathrm{X}=\mathrm{MeCN}$. 


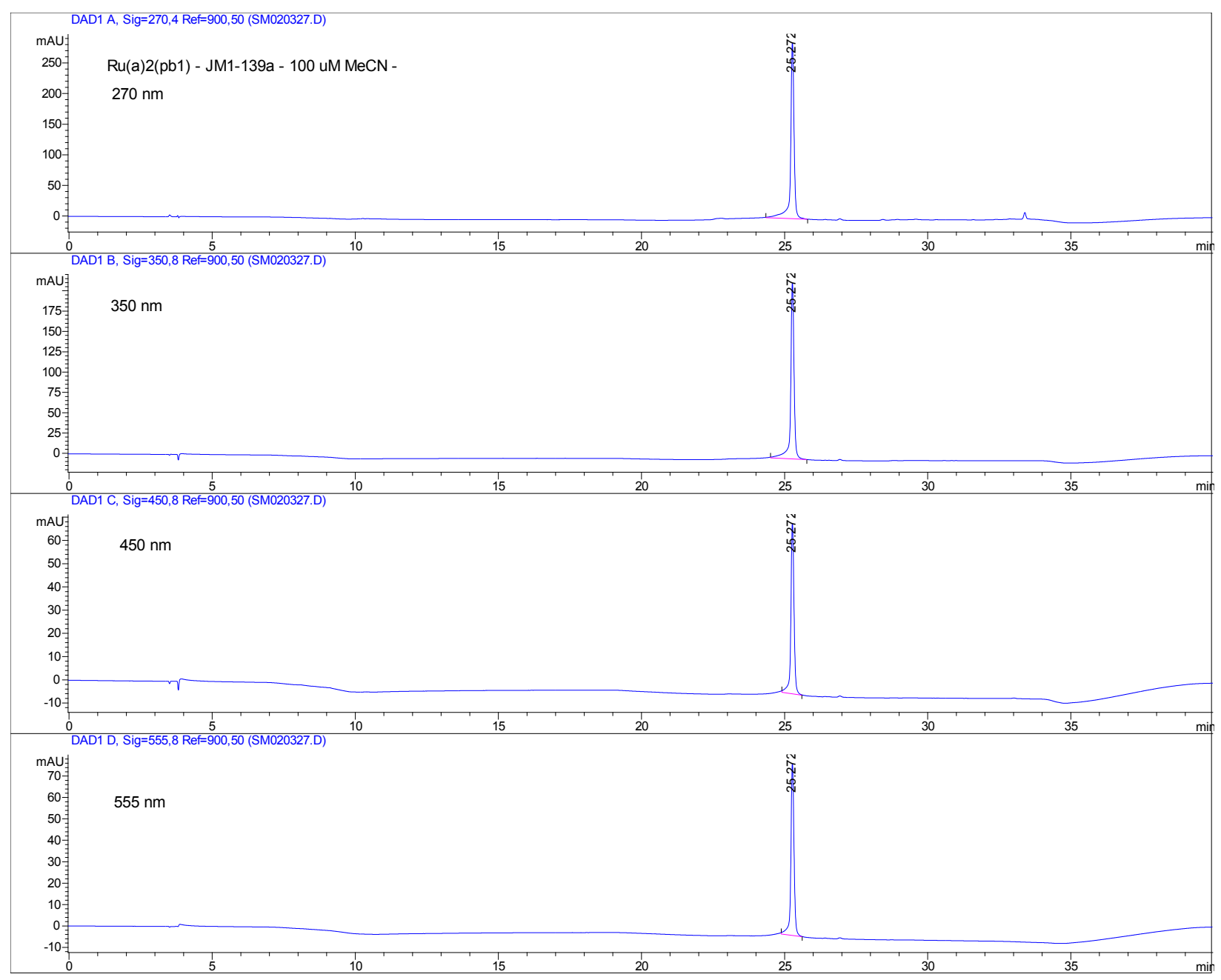

Figure S9. HPLC chromatogram of 1 collected at the following wavelengths: $270,350,450,555 \mathrm{~nm}$ (97\% purity by peak area). 


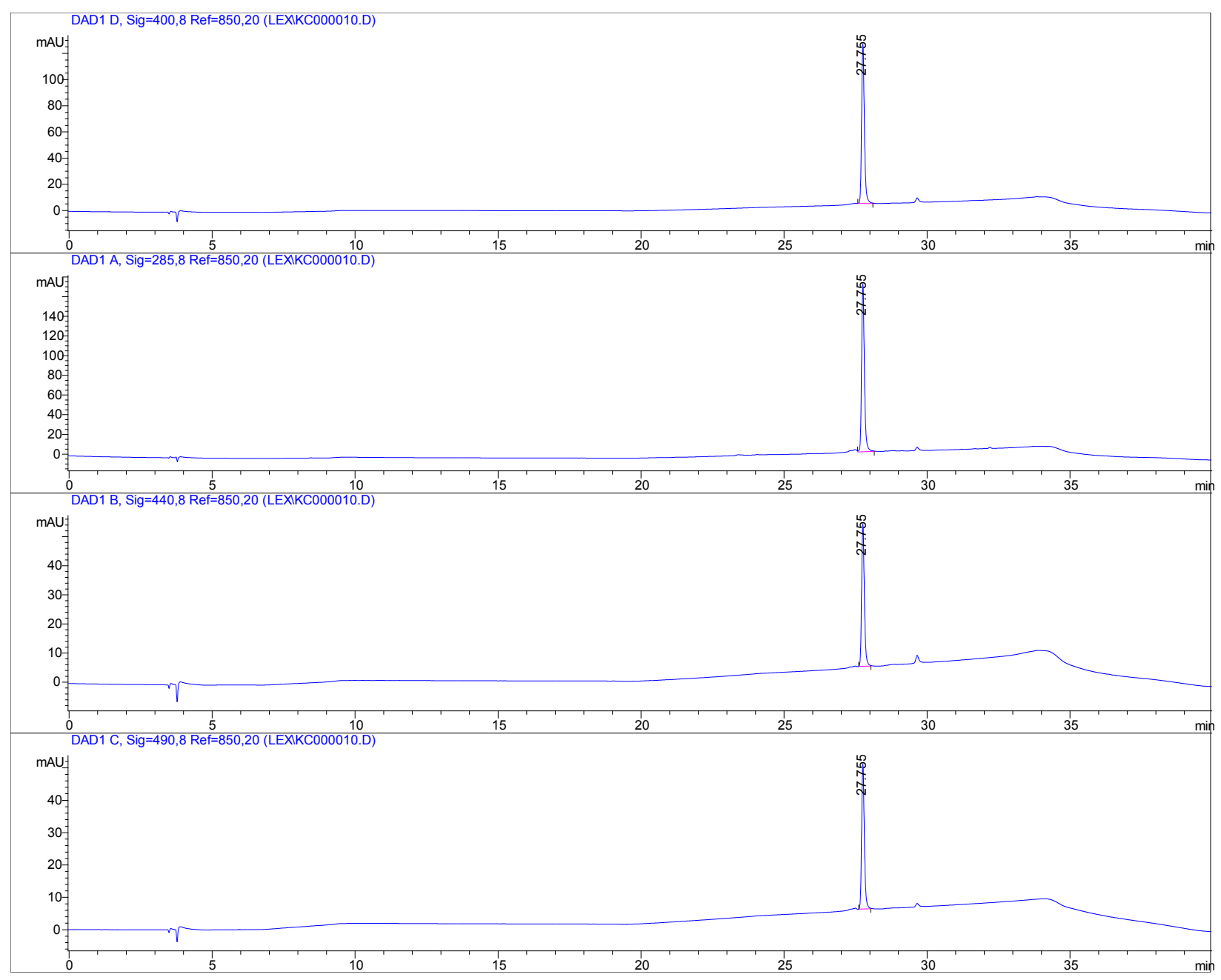

Figure Sio. HPLC chromatogram of 2 collected at the following wavelengths: 400, 285, 440, 490 $\mathrm{nm}$ (99\% purity by peak area). 


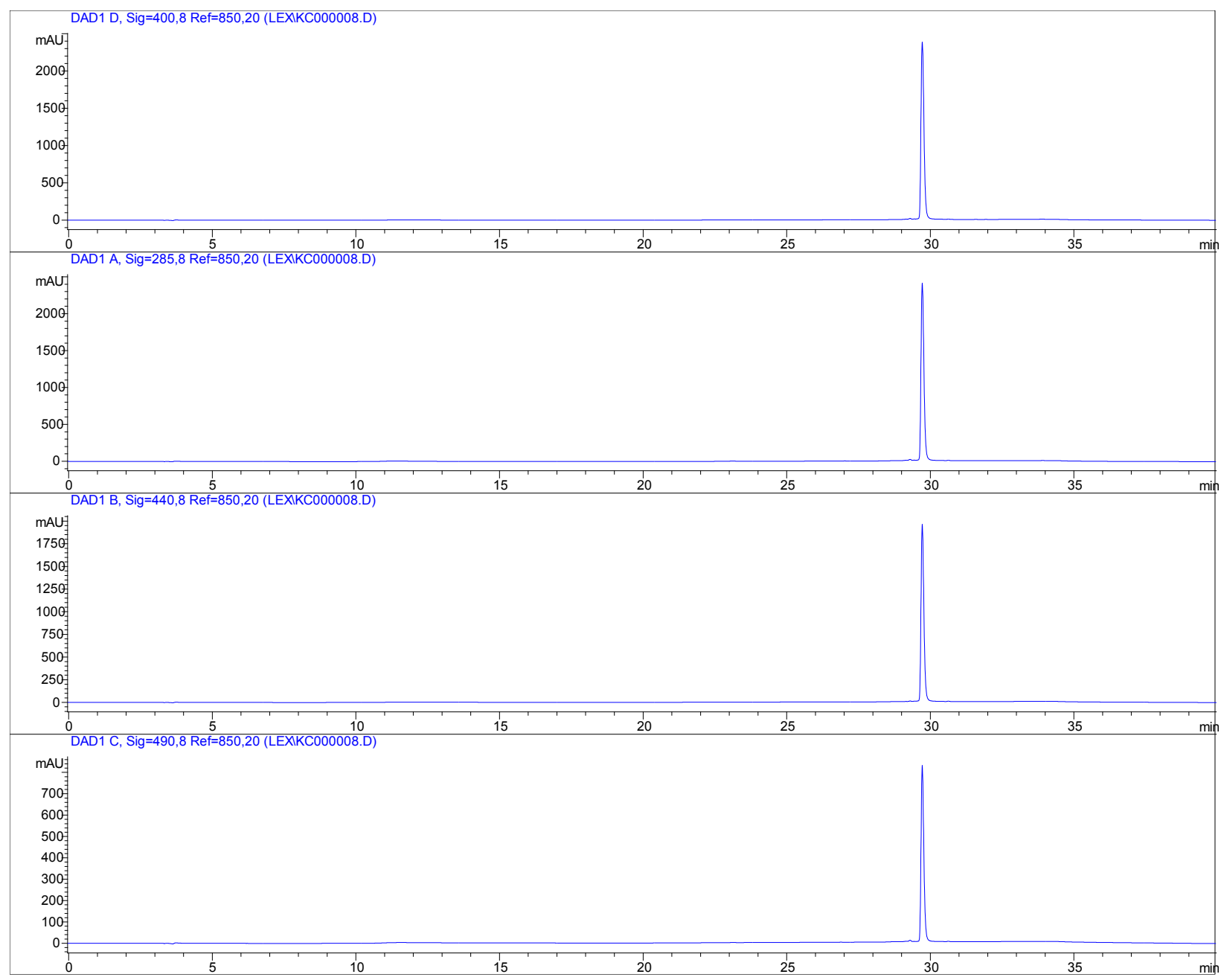

Figure S11. HPLC chromatogram of 3 collected at the following wavelengths: $400,285,440,490$ $\mathrm{nm}$ ( $98 \%$ purity by peak area). 


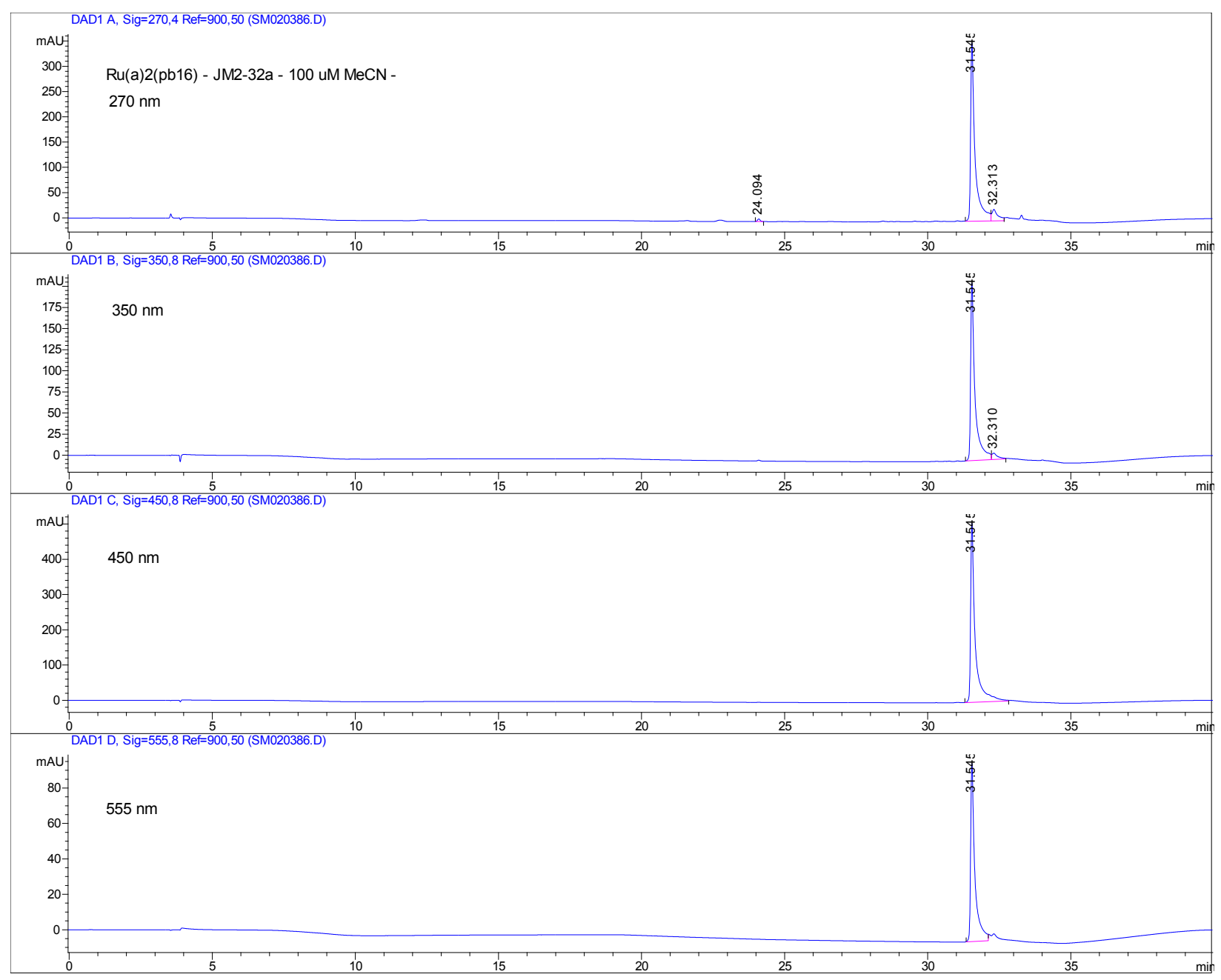

Figure S12. HPLC chromatogram of 4 collected at the following wavelengths: $270,350,450,555 \mathrm{~nm}$ (95\% purity by peak area). 


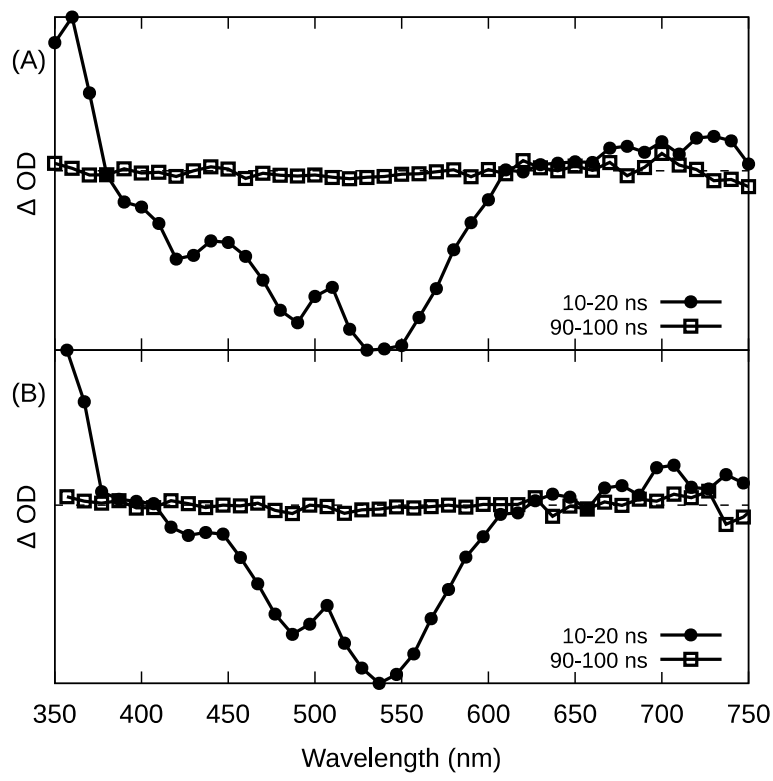

Figure $\mathrm{S}_{13}$. Comparison of the transient absorption decays for $\mathrm{Ru}(\mathrm{II}) \mathrm{C}^{\wedge} \mathrm{N}$ complex $\mathbf{1}$ collected with $\lambda_{\text {pump }}=355 \mathrm{~nm}$ (A) or $532 \mathrm{~nm}$ (B) integrated over $10 \mathrm{~ns}$ starting at 10 or $90 \mathrm{~ns}$ after the excitation pulse.

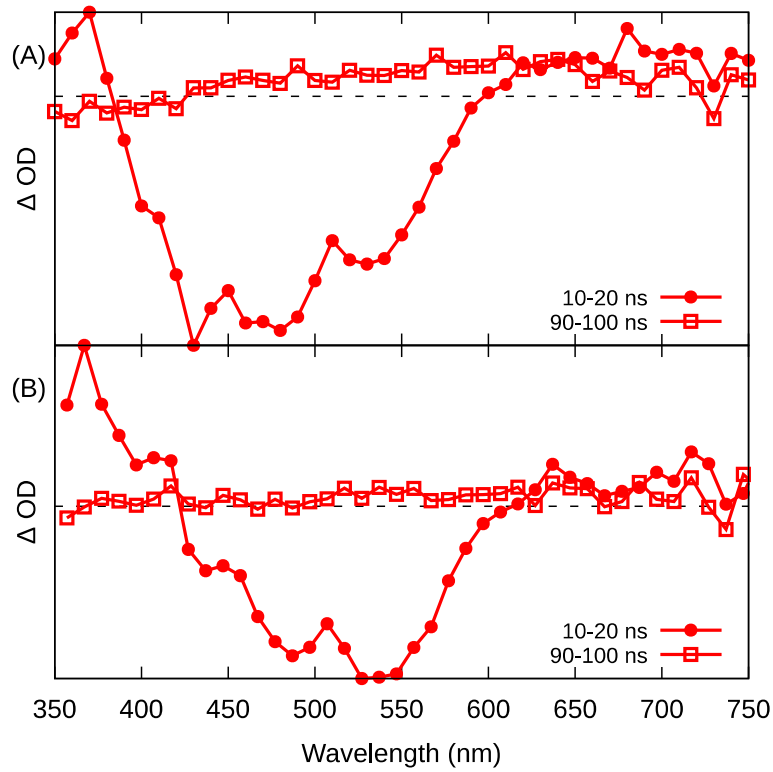

Figure S14. Comparison of the transient absorption decays for $\mathrm{Ru}(\mathrm{II}) \mathrm{C}^{\wedge} \mathrm{N}$ complex 2 collected with $\lambda_{\text {pump }}=355 \mathrm{~nm}$ (A) or $532 \mathrm{~nm}$ (B) integrated over $10 \mathrm{~ns}$ starting at 10 or $90 \mathrm{~ns}$ after the excitation pulse. 


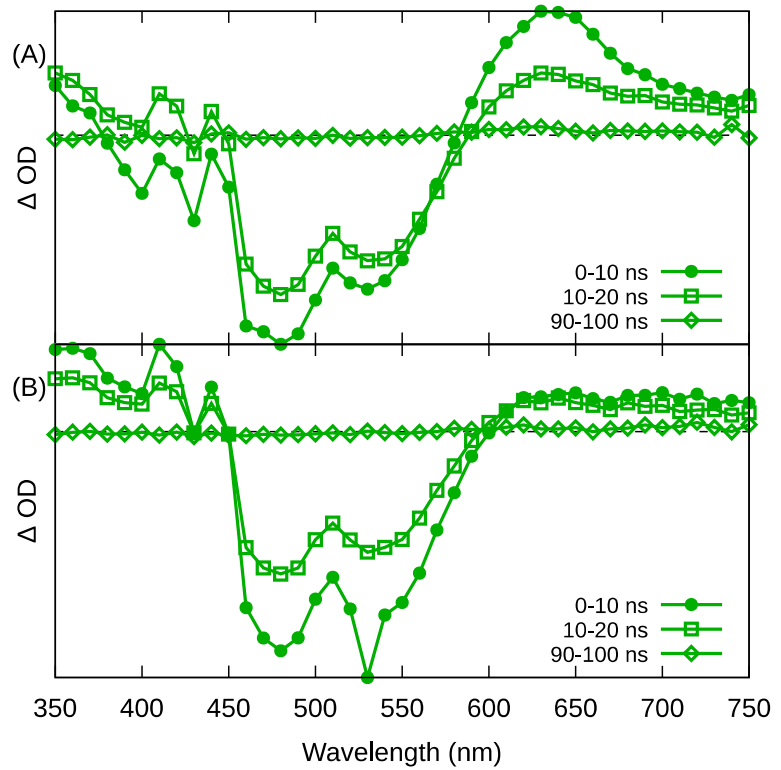

Figure S15. Comparison of the transient absorption decays for $\mathrm{Ru}(\mathrm{II}) \mathrm{C}^{\wedge} \mathrm{N}$ complex 3 collected with $\lambda_{\text {pump }}=355 \mathrm{~nm}$ (A) or $532 \mathrm{~nm}$ (B) integrated over 10 ns starting at zero delay time or 10 or $90 \mathrm{~ns}$ after the excitation pulse.

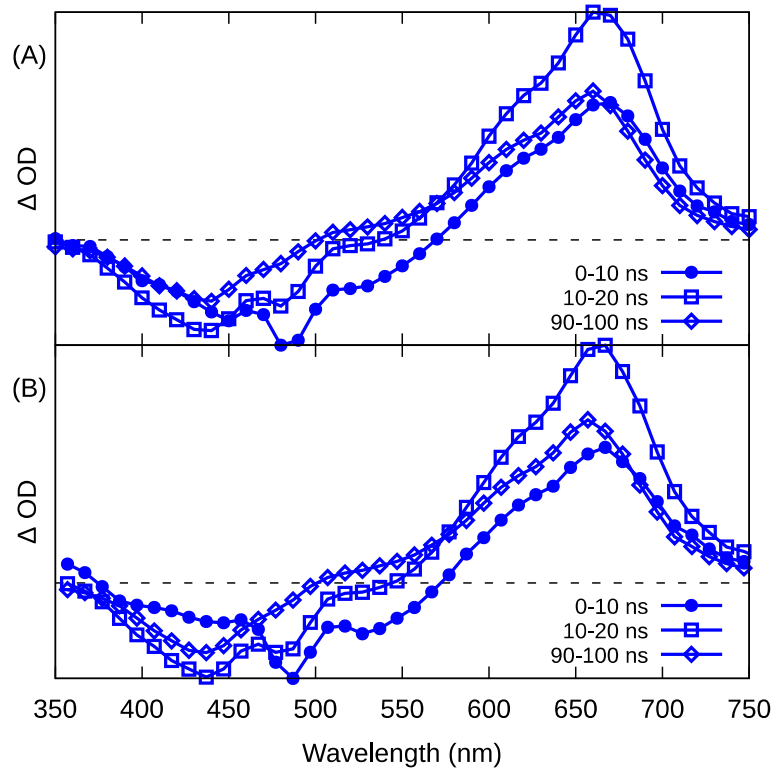

Figure S16. Comparison of the transient absorption decays for $\mathrm{Ru}(\mathrm{II}) \mathrm{C}^{\wedge} \mathrm{N}$ complex 4 collected with $\lambda_{\text {pump }}=355 \mathrm{~nm}$ (A) or $532 \mathrm{~nm}$ (B) integrated over $10 \mathrm{~ns}$ starting at zero delay time or 10 or 90 ns after the excitation pulse 


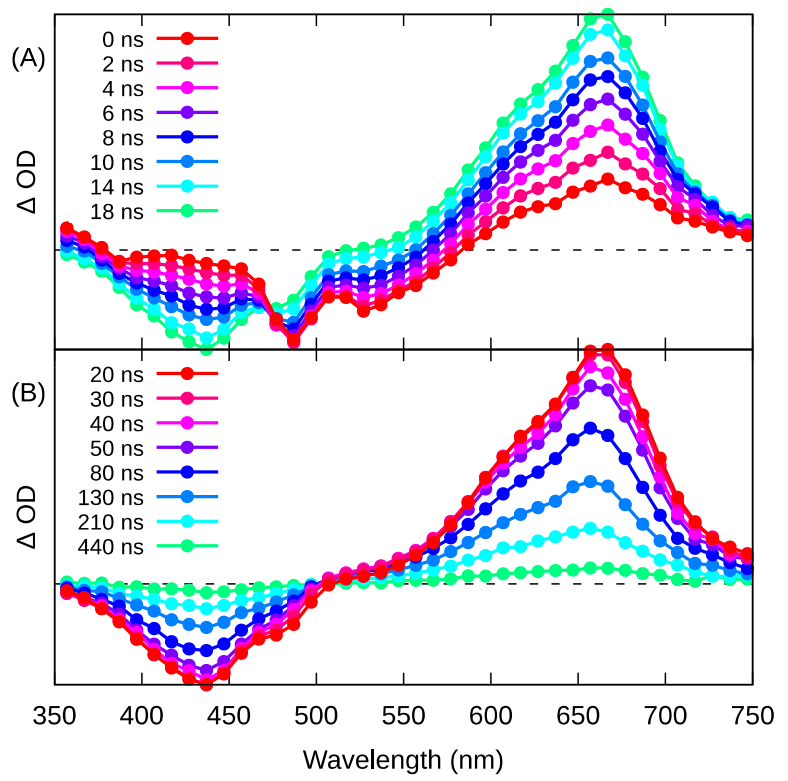

Figure $\mathrm{S} 17$. The TA spectrum of 4 excited at $532 \mathrm{~nm}$.

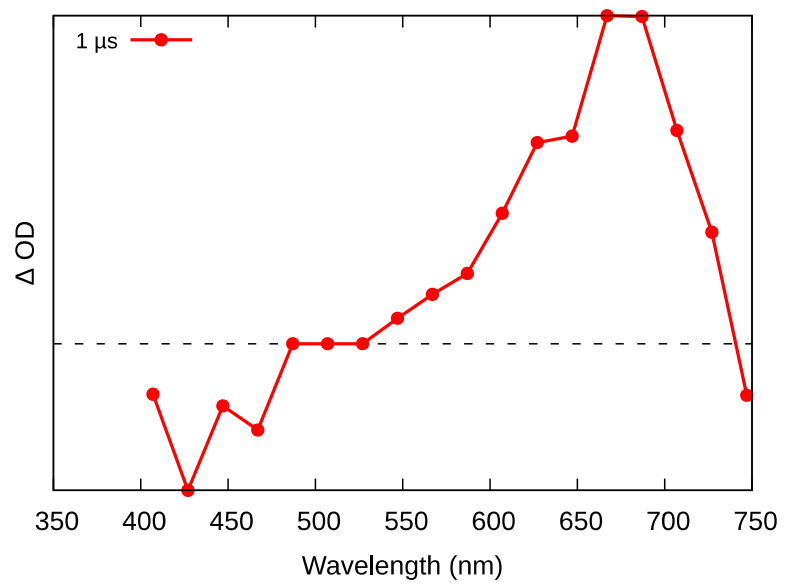

Figure S18. Transient absorption of the IBQ4T ligand only, in DMSO containing $1 \mathrm{M}$ KI. The o$1 \mu$ s slice is shown. 
Table S1: Emission Data for Complexes 1-4 in 4:1 EtOH:MeOH at $77 \mathrm{~K}^{a}$

$\begin{array}{ccccc}\text { Cmpd } & \lambda_{\mathrm{em}}, \mathrm{nm}{ }^{1} \mathrm{IL}(77 \mathrm{~K}) & \lambda_{\mathrm{em}}, \mathrm{nm}{ }^{3} \operatorname{MLCT}(77 \mathrm{~K}) & \Phi_{\mathrm{p}}{ }^{3 \operatorname{MLCT}}(77 \mathrm{~K}) & \Delta \mathrm{E}_{\mathrm{s}}, \mathrm{cm}^{-1} \\ 1 & 423(360) & 726(420) & 5.9 \times 10^{-3}(530) & 1382 \\ 2 & 456(377) & 727(420) & 5.4 \times 10^{-3}(530) & 1378 \\ 3 & 503(405) & 730(433) & 3.3 \times 10^{-3}(530) & 1276 \\ 4 & 494(418) & 732(440) & 3.8 \times 10^{-4}(530) & 1238\end{array}$

${ }^{a}$ Excitation wavelengths $(\mathrm{nm})$ are indicated in parentheses. 